\title{
Rare temperature histories and cirrus ice number density in a parcel and a one-dimensional model
}

\author{
D. M. Murphy \\ NOAA ESRL Chemical Sciences Division, Boulder, CO, USA \\ Correspondence to: D. M. Murphy (daniel.m.murphy@noaa.gov) \\ Received: 10 February 2014 - Published in Atmos. Chem. Phys. Discuss.: 29 April 2014 \\ Revised: 28 October 2014 - Accepted: 10 November 2014 - Published: 9 December 2014
}

\begin{abstract}
A parcel and a one-dimensional model are used to investigate the temperature dependence of ice crystal number density. The number of ice crystals initially formed in a cold cirrus cloud is very sensitive to the nucleation mechanism and the detailed history of cooling rates during nucleation. A possible small spread in the homogeneous freezing threshold due to varying particle composition is identified as a sensitive nucleation parameter. In a parcel model, the slow growth rate of ice crystals at low temperatures inherently leads to a strong increase in ice number density at low temperatures. This temperature dependence is not observed. The model temperature dependence occurs for a wide range of assumptions and for either homogeneous or, less strongly, heterogeneous freezing. However, the parcel model also shows that random temperature fluctuations result in an extremely wide range of ice number densities. A one-dimensional model is used to show that the rare temperature trajectories resulting in the lowest number densities are disproportionately important. Low number density ice crystals sediment and influence a large volume of air. When such fall streaks are included, the ice number becomes less sensitive to the details of nucleation than it is in a parcel model. The one-dimensional simulations have a more realistic temperature dependence than the parcel mode. The one-dimensional model also produces layers with vertical dimensions of meters even if the temperature forcing has a much broader vertical wavelength. Unlike warm clouds, cirrus clouds are frequently surrounded by supersaturated air. Sedimentation through supersaturated air increases the importance of any process that produces small numbers of ice crystals. This paper emphasizes the relatively rare temperature trajectories that produce the fewest crystals. Other processes are heterogeneous nucleation, sedimentation from
\end{abstract}

the very bottom of clouds, annealing of disordered to hexagonal ice, and entrainment.

\section{Introduction}

Cirrus clouds cover large areas of the Earth (Wang et al., 1994). They reflect a significant amount of sunlight, trap infrared heat, and affect the local heating rates and circulation of the upper troposphere (Liou, 1986). These radiative effects are sensitive to the number density of ice crystals ( $\mathrm{Fu}$ and Liou, 1993; McFarquhar et al., 2000). There are significant uncertainties in ice nucleation in cirrus clouds, that is, the mechanisms by which ice crystals form on pre-existing aerosol particles.

The most basic distinction is between homogeneous and heterogeneous freezing. Homogeneous freezing originates from a water solution droplet. Koop et al. (2000) showed that, to at least a first approximation, homogeneous freezing depends only on water activity and not on the identity of the solute. At equilibrium the water activity of the droplet is equal to the ambient relative humidity, so homogenous freezing should depend only on relative humidity, an important simplification. However, as will be shown below, the number of ice crystals is significantly changed by even small departures from the Koop et al. approximation that all solutes behave the same.

Heterogeneous freezing is initiated at a solid surface or other interface. The solid may interact with the gas phase for deposition freezing, be inside a droplet for immersion freezing, or be in other configurations. Analysis of the residuals left from evaporated ice crystals shows that heterogeneous freezing is often the dominant mechanism in high-altitude 
cirrus (Cziczo et al., 2013) or that residuals are not fully consistent with either simple heterogeneous or simple homogeneous freezing (Froyd et al., 2010).

Heterogeneous freezing requires particles with specific compositions, so a key aspect is the availability of such particles. A few heterogeneous nuclei that form ice at low supersaturation can reduce the number of ice crystals compared to homogeneous freezing, whereas many heterogeneous nuclei can enhance the number. Issues such as the competition between homogeneous and heterogeneous freezing and the effect of cooling rate have been studied extensively (DeMott et al., 1997; Jensen and Toon, 1997; Kärcher and Lohmann, 2003; Ren and MacKenzie, 2005; Kärcher et al., 2006; Barahona and Nenes, 2009; Spichtinger and Gierens, 2009c; Spichtinger and Cziczo, 2010). Extremely few heterogeneous nuclei form ice that sediments without a significant effect on the further evolution of the cloud.

Small-scale temperature fluctuations also strongly affect the number of ice crystals. Ice formation depends on the cooling rate as well as absolute humidity because water uptake by the ice crystals quenches the supersaturation that allows nucleation (Jensen and Toon, 1994). Even though their amplitude is small, the speed of small-scale temperature fluctuations creates high cooling rates that can greatly enhance the number of ice crystals (Murphy and Gary, 1995; Hoyle et al., 2005; Jensen et al., 1998, 2013a). The shape and crystal structure of the ice crystals also affects their number and especially the size distribution (Murphy, 2003; Sheridan et al., 2009).

\section{Model description}

A parcel model and a one-dimensional model are used for the calculations presented here. The parcel model is an extension of that in Murphy (2003). It tracks the nucleation and growth of ice crystals from an initial aerosol size distribution. Ice is tracked in 20 size bins logarithmically spaced between $90 \mathrm{~nm}$ and $80 \mu \mathrm{m}$. Ice growth includes free molecular, transition, and continuum flow; the Kelvin effect for small particles; and the heat of deposition or evaporation. The model does not include asymmetric growth (Zhang and Harrington, 2014). Ice is initially formed as stacking-disordered (formerly called cubic) ice and anneals to hexagonal ice. Aggregation is not included. Most model parameters are the same as in Murphy (2003). The annealing rate from stacking-disordered to hexagonal ice was reduced by a factor of 10 because subsequent data suggest a lower, albeit more complicated, rate (Murray and Bertram, 2006). The mass accommodation coefficient of water vapor on ice is not known well, with recent studies supporting values from less than 0.01 to 0.7 (Magee et al., 2006; Skrotzki et al., 2013) and possibly a range depending on the saturation ratio and crystal axis (Zhang and Harrington, 2014). Here, it is set to 0.2 for hexagonal ice and 0.4 for stacking-disordered ice on the grounds that, as a metastable phase, it must be kinetically easier to form than hexagonal ice. Sensitivity tests were conducted for many of the parameters, including the accommodation coefficient.

The one-dimensional model tracks ice crystal formation events rather than size bins. The main reason to track events is that it turns out that small amounts of sedimentation are important for the evolution of the model cloud. By tracking events the ice crystals can sediment by fractions of the vertical model spacing, and there is therefore no numerical vertical diffusion of ice crystals (Jensen et al., 2010; Sölch and Kärcher, 2010). Model physics such as the nucleation rate and ice growth equations were the same in the parcel and one-dimensional models. The parcel model includes kinetically limited water uptake and loss by aerosols.

Water vapor, temperature, and other state parameters were tracked at a fixed vertical spacing. At each time step, an event was generated if the integrated probability of nucleation exceeded 0.02 per liter. Thereafter, the ice crystal diameter and sedimentation of that particle event were tracked as continuous variables, whereas the water vapor for growth (evaporation) was taken from (given to) the nearest bins according to the position. For example, if a growing ice crystal event was exactly in the middle of a bin, all the water was taken from that bin, whereas if it was at a bin boundary, half the water was taken from each bin.

A detail is that the nucleation probability must be integrated over time and vertical distance in order to make nucleation events independent of the size of a time step or the water vapor grid spacing. When the integral of the nucleation probability reaches a threshold, an event is generated at the most probable location and the integrated nucleation probability reduced by 1 at that location. As a simple example, consider only three vertical bins in which, because of imposed cooling and water vapor, the probability of nucleation has slowly accumulated to 0.3 per $50 \mathrm{~L}$ in the top and bottom bins and 0.5 in the middle bin. Because the total of 1.1 exceeds 1 , a nucleation event is generated in the most probable (middle) bin. Following this, the nucleation probability is 0.3 in the top and bottom bins and negative 0.5 in the middle bin. A few time steps later, the integrated probability might be 0.6 in the top bin, 0.0 in the middle bin, and 0.5 in the bottom bin, and the next event will take place in the top bin. During rapid nucleation, the total probability can increase in a single time step by more than one ice crystal per $50 \mathrm{~L}$. In that case, ice events were initiated in more than one vertical bin and the surface area and mass of the subsequent ice were weighted according to the probability. A typical model run tracked perhaps 20000 formation events. Ice crystals were formed as stacking-disordered ice and annealed stochastically to hexagonal ice depending on integrated probabilities analogous to those for ice nucleation. For computational reasons, every few time steps, ice events with essentially identical sizes and (sedimented) vertical positions were combined. 


\section{Parcel model results}

Parcel model simulations were run for frost point temperatures ranging from 185 to $230 \mathrm{~K}$. At each temperature, 80 simulations were run with various seeds for the random number generator that initializes the fractal small-scale temperature fluctuations. The fluctuations have a Hurst exponent of about 0.7 . This gives a realistic short-term autocorrelation. As in Murphy (2003), temperature fluctuations with periods shorter than 2 min were removed. The amplitude of a fractal depends on the period. For the simulations here, some representative amplitudes were standard deviations of $0.045 \mathrm{~K}$ over $10 \mathrm{~min}, 0.20 \mathrm{~K}$ over $1 \mathrm{~h}$, and $1.33 \mathrm{~K}$ over $10 \mathrm{~h}$. In terms of a power spectrum, one may compare the 1 and $10 \mathrm{~h}$ variances: $\log _{10}\left((0.2 / 1.33)^{2}\right) \approx-1.65$ for a slope of about $-5 / 3$. A $3.2 \mathrm{~K}$ cooling with a $12 \mathrm{~h}$, half-sine pattern was added to the temperature fluctuations; otherwise many random fluctuations would never generate a model cloud. The same set of temperature fluctuations were repeated at each initial temperature. All simulations were recalculated for a variety of model parameters and assumptions about homogeneous and heterogeneous ice nucleation processes.

One striking result is that various temperature histories generated a very wide range of ice crystal number densities for the same model assumptions. Figure 1 shows a histogram of the maximum ice number density with homogeneous freezing for temperature histories with ice saturation of 1.25 at $196 \mathrm{~K}$ (frost point of $197.4 \mathrm{~K}$ ) along with a subset of the model temperature trajectories. Jensen et al. (2010) also found wide distributions of ice number density, depending on the relative phase of waves creating temperature fluctuations. Low ice number densities can be generated by temperature histories that spend a very short amount of time above the ice nucleation point (Spichtinger and Krämer, 2013). Wide distributions of number density are also evident in various portions of one- and two-dimensional model fields (Lin et al., 2005; Spichtinger and Gierens, 2009b).

The absolute number of ice crystals in the model is sensitive to several of the assumed parameters, especially the accommodation coefficient. However, the results here emphasize trends with temperature and probability distributions due to temperature fluctuations. Such trends and distributions are much less sensitive to model parameters.

Figure 2 shows results from the parcel model for a range of temperatures. The homogeneous nucleation calculations show many more ice crystals at low temperatures. This is because there is less water vapor at lower temperatures, causing slower growth of the ice crystals. With slower growth, more time elapses before the ice surface area grows enough to reduce the supersaturation and suppress further nucleation. With a longer nucleation event, more ice crystals form. This is a very fundamental temperature dependence and occurs when a variety of model parameters are changed (blue lines). The slope of the temperature dependence is similar to Kärcher (2002, Fig. 3) or Spichtinger and Gierens (2009a)
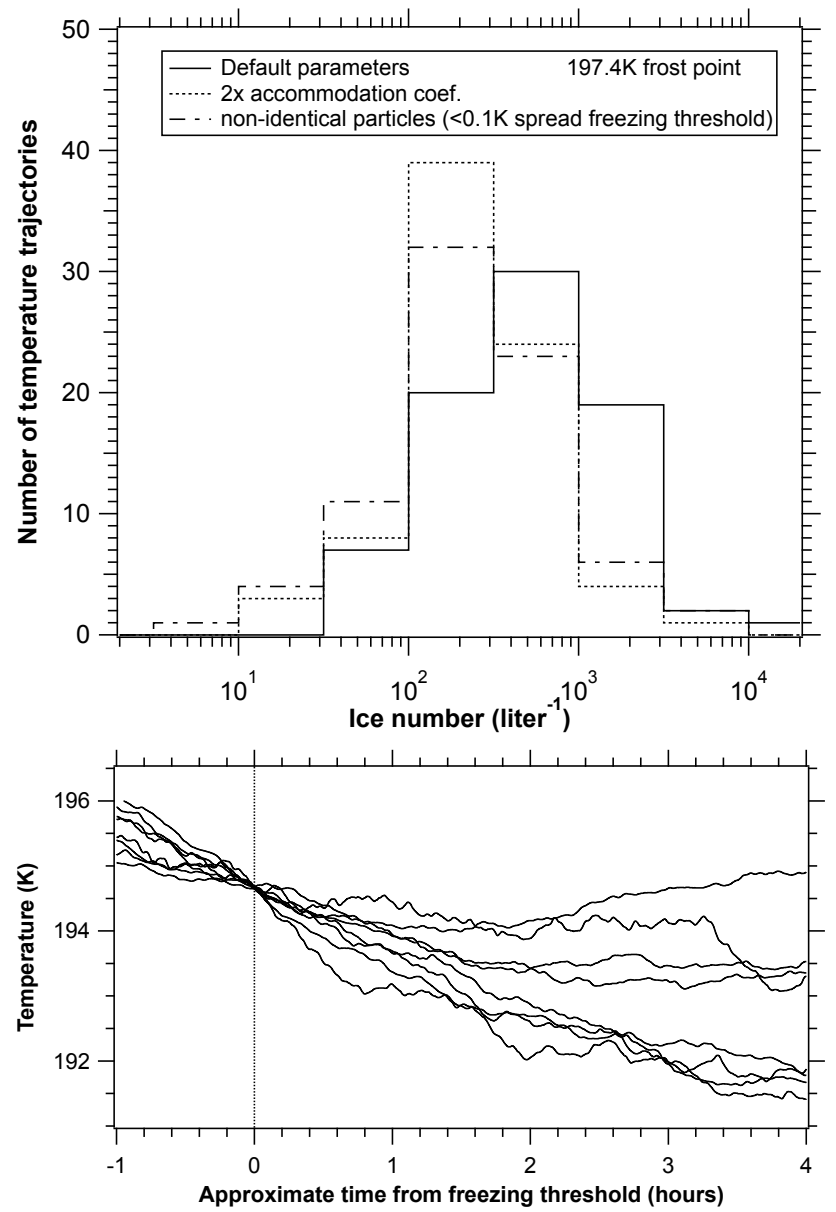

Figure 1. Histogram of ice number density generated by homogeneous freezing in a parcel model. Also shown are the first 8 of the 80 temperature trajectories, all with same amplitude and fractal slope of temperature fluctuations. Doubling the accommodation coefficient of water on the growing ice crystals systematically reduces the number density, as does assuming that there is a very small spread in the water activity at freezing. However, the phase and slope of small-scale fluctuations near the homogeneous freezing threshold creates a histogram that is much wider than the effect of changing this or other model parameters.

but represents the median of a wide distribution rather than a single vertical velocity.

The inset in Fig. 2a explores which are the most sensitive parameters for ice crystal number density. The sensitivity to the upper value of the default parameters is almost a mirror image of those shown. Ice number is extremely insensitive to the absolute nucleation rate. Ice number becomes sensitive to the accommodation coefficient of water at values below about 0.2. Model runs with an accommodation coefficient that became small near saturation ratios of 1.0 (simplified from Zhang and Harrington, 2014) made almost no difference to ice number; the number is determined mostly by the accommodation coefficient near the nucleation 

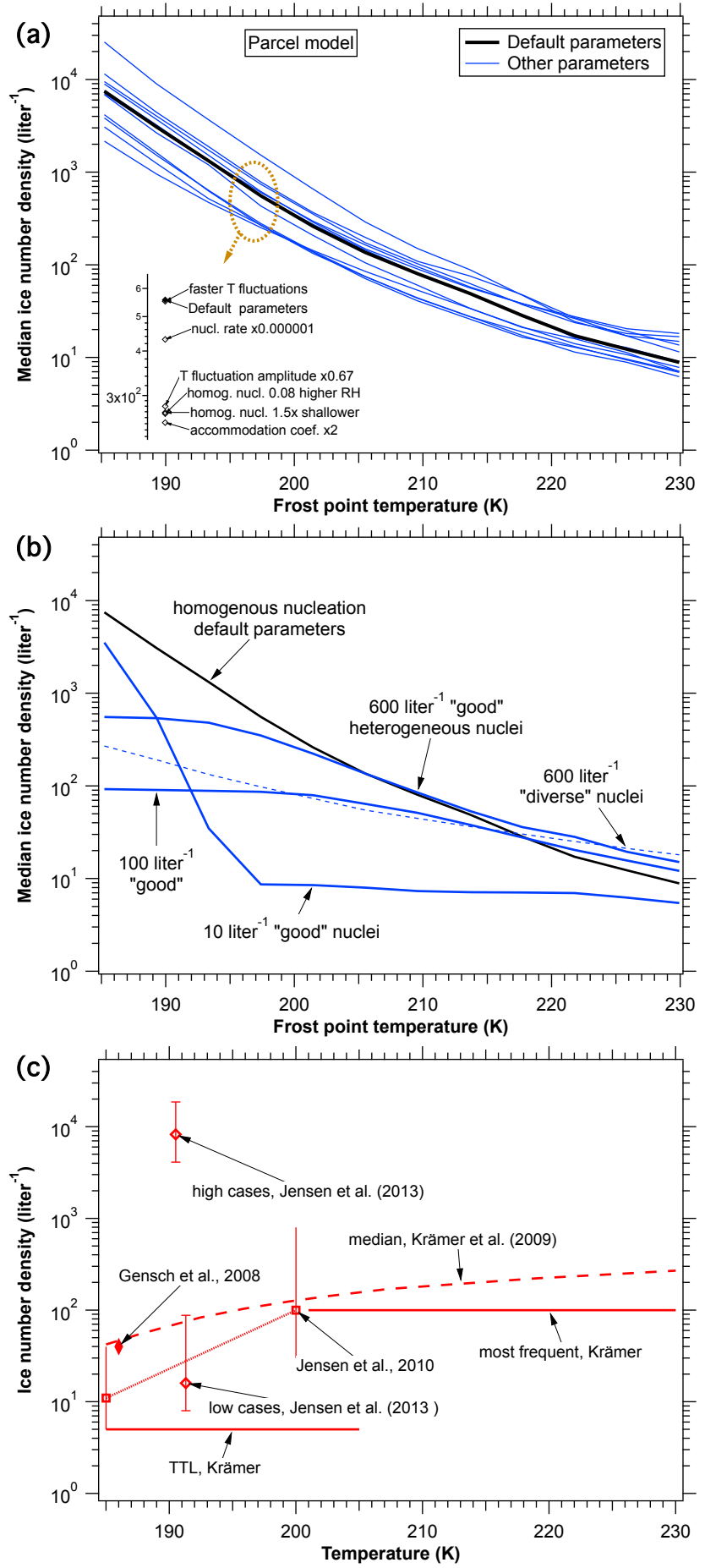

Figure 2. Parcel model results for the temperature dependence of ice crystal number density along with results from observations. In (b), "good" heterogeneous nuclei freeze at an ice supersaturation of $1.3 \pm 0.02$, whereas "diverse" nuclei are uniformly distributed between supersaturations of 1.3 and 1.65. Panel (c) shows observations described in Gensch et al., 2008, Krämer et al., 2009, Jensen et al., 2010, 2013b, and typical values from Krämer (personal communication, 2014). Ranges in (c) are approximated from the data in the Jensen et al. papers. In this temperature range, homogeneous freezing occurs about $3 \mathrm{~K}$ below the frost point. TTL is the Tropical Tropopause Layer.

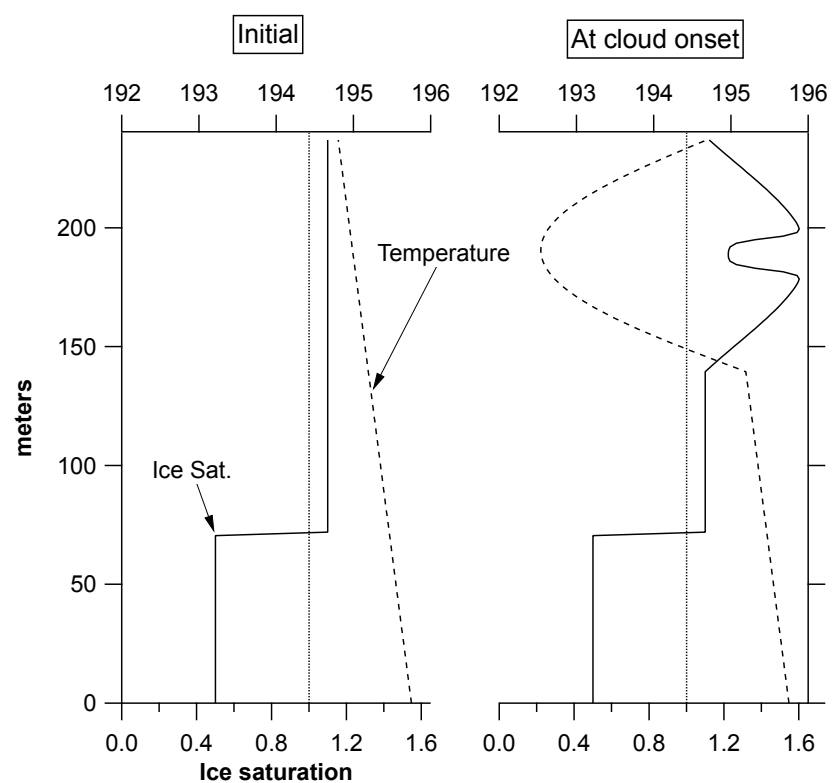

Figure 3. Vertical profiles showing how the one-dimensional model was initialized and cooling imposed. The imposed cooling used a smooth vertical profile over $100 \mathrm{~m}$ but fluctuated in time. One can picture the half-sine temperature perturbation oscillation with an amplitude that followed one of the temperature trajectories in Fig. 1.

threshold. Saturation-dependent accommodation coefficients become important in other situations. Ice number is moderately sensitive to displacing the homogeneous nucleation point by a small amount of supersaturation. "Faster T fluctuations" means that the fractal temperature fluctuations were smoothed at 1 rather than 2 min.

Of interest is the sensitivity to the slope of the nucleation rate. The Koop et al. (2000) nucleation rate is a very steep function of relative humidity at the nucleation threshold but is not quite a step function. Artificially increasing or lowering the slope with supersaturation has a much larger impact on the number of ice crystals than the nucleation rate itself. This is potentially important on the side of reducing the slope. If the Koop et al. result that water activity controls freezing is only a first approximation, then particles with different compositions should freeze at slightly different supersaturations. High molecular weight polymers have a larger freezing point depression than simple molecules (Zobrist et al., 2003). A small range of freezing activities would be equivalent to a reduced slope with temperature, and the parcel model shows that the ice number is quite sensitive to this. Because the Koop et al. (2000) nucleation rate is extremely steep, the 0.67 slope case shown in Fig. 2a means that the relative humidity at freezing is the same within about $1 \%$ for particles of various compositions. This is equivalent to a spread in freezing point depression of less than $0.1 \mathrm{~K}$, well within the scatter of experimental data. Yet that reduction in slope reduced the number of ice crystals by about a factor of 2 . Larger spreads 
in the water activity at freezing (not shown) led to much larger reductions in the number of ice crystals.

Figure $2 b$ shows results from several heterogeneous cases. As expected, the ice number density is sensitive to the number of heterogeneous nuclei. Also as expected, if there are too few nuclei at very low temperatures, then the heterogeneous nuclei do not deplete the water vapor enough to prevent homogeneous freezing (Jensen and Toon, 1997; Kärcher and Lohmann, 2003). Figure $2 \mathrm{~b}$ also compares cases where the heterogeneous nuclei are essentially identical or freeze over a range of relative humidities ("diverse nuclei" in the figure). With these and other assumptions about heterogeneous freezing, the number of ice crystals always increased at lower temperatures. The range of ice nuclei concentrations in Fig. 2 is intended to illustrate model behavior rather than assert what concentrations are in the atmosphere.

Figure $2 \mathrm{c}$ shows some published results on observed ice number density. There are only a few studies due to the realization that ice shattering on aircraft probes invalidates much of the older data (Jensen et al., 2009). There are several points of comparison. First, the results here support the contention in Jensen et al. (2013b) that the high ice number densities observed in thin layers near $190 \mathrm{~K}$ can be explained by homogeneous freezing. Second, it is extremely hard in a parcel model to reproduce the low end of the observed ice number densities below about $190 \mathrm{~K}$, regardless of the number of heterogeneous ice nuclei. It might be possible if the accommodation coefficient were unity and other parameters were adjusted, but then the model could not match observations at warmer temperatures. Third, some of the highest ice number densities observed in Krämer et al. (2009) above about $210 \mathrm{~K}$ cannot be reproduced by the parcel model. Some of these high number densities were measured in lee wave clouds (Krämer, personal communication, 2014). Ice shatter also becomes more of a concern at warmer temperatures, where there are large crystals more likely to hit the probe.

Fourth and most important, neither homogeneous nor heterogeneous freezing in a parcel model can reproduce the observed slope in either Krämer et al. (2009) or Jensen et al. (2012). No simple tuning of the parcel model parameters can change the modeled increase in ice number at low temperatures. The slope is a fundamental consequence of less water vapor at lower temperatures. The only way to reverse the slope would be if some parameters, such as the number of ice nuclei or the accommodation coefficient, were themselves functions of temperature. Even so, the temperature dependence of the parameters would have to be very strong to overcome the basic increase in ice number at lower temperatures.

\section{One-dimensional model}

The failure of a parcel model to reproduce the observed temperature dependence of the ice crystal number suggests that
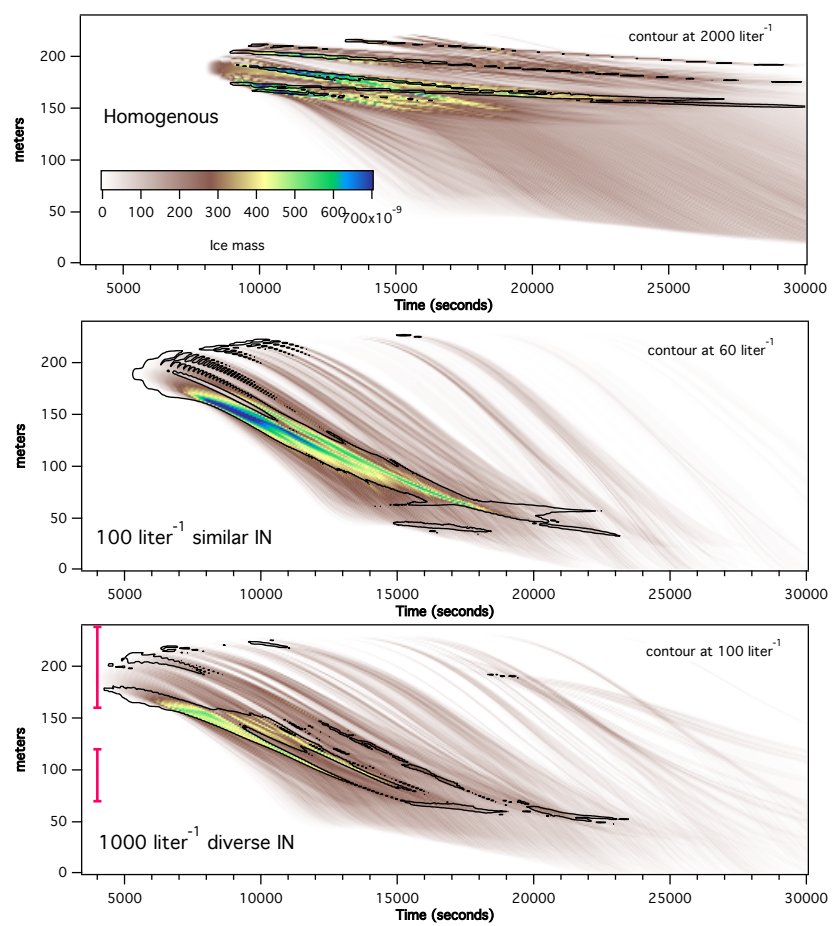

Figure 4. One-dimensional model results for three assumptions about ice nucleation and the same imposed cooling. Contours show ice crystal concentration in $\mathrm{L}^{-1}$. Color shows ice mass concentration with the same scale for all three panels.

there may be important ice cloud microphysics not captured by a parcel model. The most obvious candidate is the sedimentation of ice crystals. A model with at least one dimension is necessary to investigate sedimentation.

Figure 3 shows the configuration of the one-dimensional model runs. An initial saturation ratio of 1.1 is imposed except in a subsaturated region near the bottom of the model domain so that falling ice crystals can evaporate. Then one of the same temperature trajectories used in the parcel model is imposed over a $100 \mathrm{~m}$ thick layer, with a maximum amplitude at the center of the layer and a smooth transition to 0 above and below that. A slightly supersaturated layer remains below the imposed temperature fluctuation. The righthand profiles in Fig. 3 show the saturation profile just as ice starts to nucleate and grow near the center of the cooled layer, causing a dip in saturation ratio at the $200 \mathrm{~m}$ vertical tick.

Figure 4 shows sample results from the one-dimensional model for one of the imposed temperature profiles. There are differences but more importantly similarities when different assumptions about ice nucleation are made.

One difference is that the cloud in homogeneous cooling forms later in time because it requires a higher ice supersaturation. Second, the number of ice crystals formed (contours) is much lower when heterogeneous ice nuclei are present. Third, the homogeneous freezing case is less striated than the heterogeneous cases. 
There are important similarities. Despite a range of more than a factor of 20 in peak ice number, the peak ice mass densities are within $40 \%$ for the different types of ice nucleation in the three panels. For all cases, layers and fall streaks are generated that are far narrower than the vertical scale of the imposed cooling (Fig. 3). On this plot of altitude versus time, the slopes of the fall streaks at around $15000 \mathrm{~s}$ are also similar, meaning that the fall speeds are similar.

A final similarity is that, in this model, the fall streaks are often generated in layers that are slightly displaced from the layers that produce large numbers of ice crystals. This is most visible in the diverse nuclei (bottom) panel, but there is also a nearly complete but less visible displacement between high number and fall streak layers in the homogeneous freezing (top) panel. Only with a few good ice nuclei do the most productive nucleation events generate fall streaks, and even then the fall rate of the number density (contours) is perhaps half the fall rate of the mass (color).

In hindsight, there must often be a difference between layers and times that produce high number density and those that produce fall streaks. The high number density ice crystals are small and usually do not fall fast enough to reach supersaturated regions where they can continue to grow. It is worth thinking about how this relates to the probability distributions of the parcel model in Fig. 1. Because the imposed cooling has different amplitudes at different altitudes, each layer will reach a given nucleation threshold at a different point in the time history. Some will reach it during a rapid jump in temperature, some at a slow point. It is similar to using different temperature histories. Figure 1 shows that there are always a few temperature histories that produce low ice numbers, even in homogeneous freezing that usually creates high number densities.

These rare freezing events that produce fall streaks are disproportionately important because the falling crystals influence a much larger volume of air than those that do not fall. Exactly how much more important will depend on the initial vertical temperature and humidity profiles. The model does give a key result: these rare low number density events can still generate fall streaks even if they are between or falling through high number density layers. Conversely, high number density layers can form in between layers with a lower number, a feature that has been observed previously (Jensen et al., 2013b).

Figure 5 shows ice number densities from the onedimensional model analogous to the parcel model in Fig. 2. The ice number densities within the upper, cooled layer follow the same patterns as the parcel model. This is true for both the temperature dependence of each case and the relative magnitudes of the various cases. The absolute values are lower in the one-dimensional model because the vertical averaging includes both high number density layers and layers with few ice crystals.

The averaging layer below the cooled region considers fall streaks. Here, the number densities are much lower. The het-

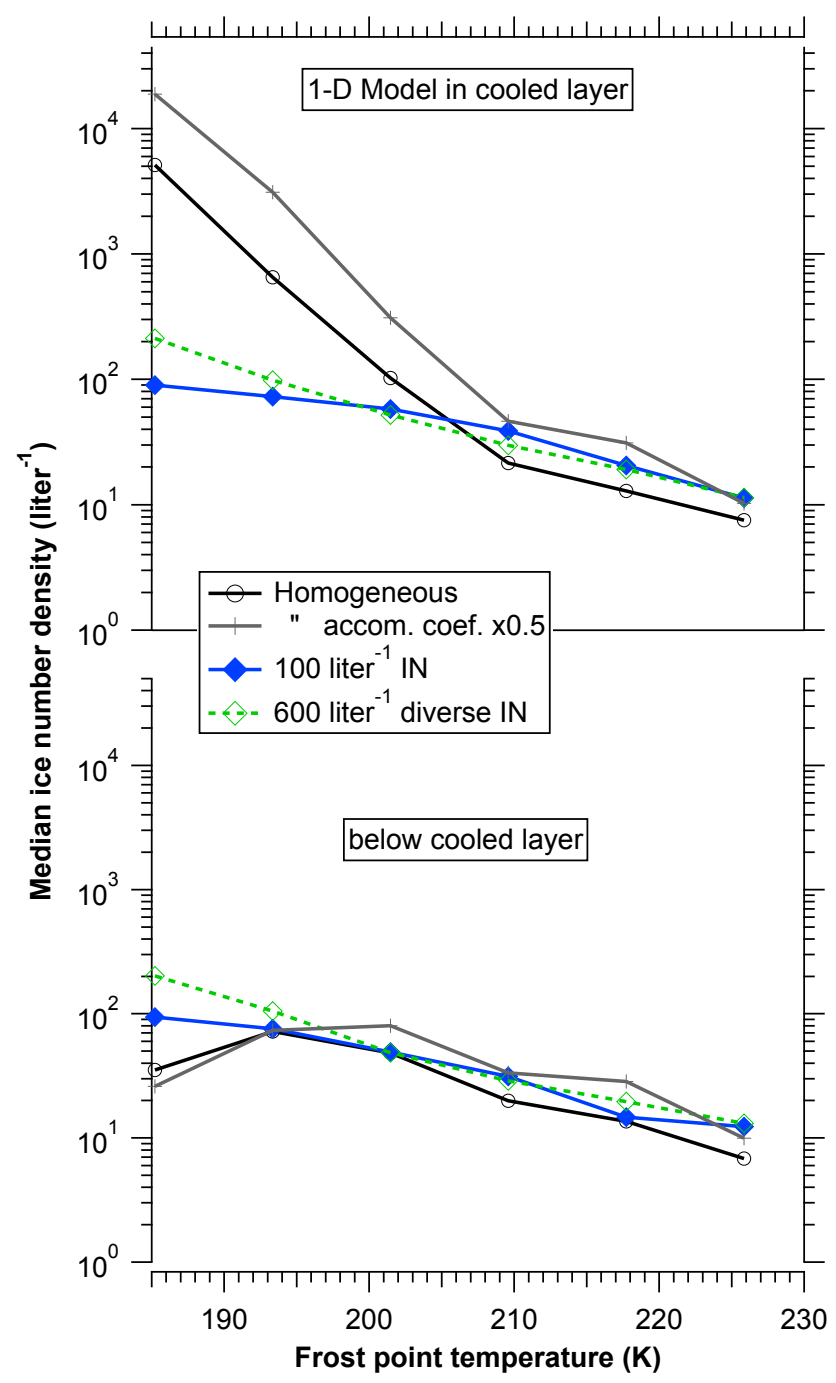

Figure 5. Ice number densities in the one-dimensional model. The values are the median over 20 temperature histories of the maximum in time averaged over vertical range either in or below the layer with imposed cooling. These ranges are indicated in Fig. 4. The axis ranges are the same as in Fig. 2.

erogeneous cases have a slightly smaller temperature dependence: a factor of about 5 over the temperature range instead of a factor of 10 . The homogeneous case is completely different below the imposed cooling than within it. It is not clear whether the maximum near $200 \mathrm{~K}$ is robust or a feature of the initial profile in the model. However, the absence of very high number densities below $200 \mathrm{~K}$ should be robust. With very little water available at cold temperatures, only regions with few particles can grow large enough crystals to produce fall streaks. The sensitivity to the accommodation coefficient is also much smaller in the fall streaks than in the upper layer.

The one-dimensional model produced a remarkably fine vertical structure from a much smoother temperature profile. A vertical resolution for water vapor concentration of about 
$2 \mathrm{~m}$ was found to be necessary even though the falling ice crystals were tracked to fractions of the grid spacing. The generation of a fine vertical structure in cirrus clouds has been seen previously. The sedimenting NAT (nitric acid trihydrate) crystals in Fueglistaler et al. (2002) required fine vertical resolution at the base of the cloud. They used a $1 \mathrm{~cm}$ (!) vertical resolution near cloud base, although no tests were done to see if such fine resolution was necessary (S. Fueglistaler, personal communication, 2013). Lin et al. (2005) found that $1 \mathrm{~m}$ vertical spacing was necessary in a cirrus cloud model with broad uplift. Spichtinger and Gierens (2009a) and Jensen et al. (2012) found that $10 \mathrm{~m}$ was necessary, again without the boundary conditions changing that rapidly in the vertical.

There are two reasons for the fine vertical structure. First, ice formation is very sensitive to the cooling rate as a nucleation threshold is crossed, so small variations in temperature history can produce large variations in ice number density. Second, sedimentation acts to amplify small vertical differences in ice crystal size into much larger fall streaks.

The one-dimensional model is still missing some important physics. Simply looking at cirrus clouds shows that fall streaks are horizontally patchy and curved, neither of which can be captured in a one-dimensional model. Wind shear is important to cirrus clouds (Spichtinger and Gierens, 2009b). Radiation-induced turbulence affects the generation of large particles and fall streaks (Gu and Liou, 2000), and the radiative properties are themselves sensitive to ice crystal size (Stackhouse and Stephens, 1991). Neither process is easy to capture in one dimension.

The vertical profiles of saturation and cooling used here in the one-dimensional model are obviously arbitrary. Trying to find a more realistic profile is limited both by the inherent limitations of working in one dimension and a lack of observations. There are few observations of upper-tropospheric temperatures on timescales of $1 \mathrm{~min}$ and horizontal scales well below $1 \mathrm{~km}$. Even when an aircraft can measure a slice of temperature profiles, translating the observed temperatures into those experienced by an air parcel depends on unmeasured phase relationships between waves of different frequencies (Bacmeister et al., 1999). Similar issues can arise for ground-based remote sensing of a single point.

\section{Discussion and conclusions}

The one-dimensional model results presented here are in many respects similar to a model of NAT crystals in the polar stratosphere (Fueglistaler et al., 2002). In an environment with much slower crystal growth than even the coldest cirrus cloud, Fueglistaler et al. found that sedimentation out of a "mother cloud" into a supersaturated layer could produce a few large NAT crystals. The number of sedimenting NAT crystals was insensitive to assumptions about the nucleation mechanism. The reason was the supersaturated region below the cloud. Any crystal that managed to make its way into this layer grew and accelerated down from the cloud. The physics of those falling crystals was determined by mixing at the bottom of the cloud and the growth conditions below the cloud, not the nucleation conditions in the cloud. This work suggests that a similar process often occurs for cirrus clouds. Besides the bottom of the cloud, this work suggests that the variety of temperature histories leads to some cloud layers with low ice number density, and these layers also produce falling crystals. Model runs at a pressure and temperature characteristic of polar-stratospheric clouds show similar processes to the tropopause conditions shown here.

There is a fundamental difference in sedimentation from cirrus clouds compared to warm liquid clouds. The air around a warm cloud is subsaturated, whereas the high supersaturations required for ice nucleation mean that the air around a newly formed cirrus cloud is supersaturated. Mixing and entrainment at the base or edges of a warm cloud causes the evaporation of water droplets. In contrast, mixing and entrainment at the base or edges of a cirrus cloud causes the growth of ice crystals near the edge while simultaneously reducing their number density and hence competition for vapor. This can induce sedimentation from the base and periphery of the cloud, very unlike a warm cloud. Large areas surrounding cirrus clouds in the upper troposphere are supersaturated (e.g., Vay et al., 2000; Ström et al., 2003; Krämer et al., 2009; Diao et al., 2013).

Sedimentation has several roles in cold cirrus clouds (Spichtinger and Gierens, 2009b). Depending on the environment, sedimentation can limit (Kärcher, 2002) or extend (Luo et al., 2003) the lifetime of very thin cirrus clouds. For some ranges of temperature fluctuations, a balance can be achieved between nucleation and sedimentation (Barahona and Nenes, 2011). Here, sedimentation is a mechanism for amplifying the importance of conditions that produce only a few ice crystals.

The very low ice number densities sometimes observed below $200 \mathrm{~K}$ can be produced in fall streaks, as also found by Jensen et al. (2012). The picture developed here of a cold cirrus cloud (below perhaps $210 \mathrm{~K}$ ) is the following: the reason aircraft observations usually measure low ice number density is that the falling crystals sweep out a much larger volume than the ones that stay put. Jensen et al. (2013a) suggested that a few heterogeneous nuclei could initiate fall streaks even if there are not enough such nuclei to suppress homogeneous nucleation. The model here generalizes that fall streaks are produced by any time or place that makes a few large particles. These regions of few crystals might result from heterogeneous nucleation, temperature blips that happened to produce only a few ice crystals from homogeneous nucleation, or mixing at the bottom or edge of a cloud. The number and mass of ice crystals in such fall streaks is fairly insensitive to how they were produced.

There may be other observational tests of the importance of sedimentation besides a comparison with observed 
ice number densities. Using statistics on the size of regions containing supersaturation and/or ice crystals, Diao et al. (2013) estimated that mature or evaporating cirrus are about seven times more prevalent than nucleation regions. Although their mature and evaporations classifications are not exactly comparable to fall streaks, it does support the notion that, throughout most of a cirrus cloud, the number of ice crystals is not determined by nucleation at that spot. A lidar with high spatial resolution could probably observe whether the fall streaks originate from locations slightly displaced from the high number density layers. Such an observation might constrain the nucleation mechanism: in the model, only nucleation on a few good ice nuclei created fall streaks coincident with the highest number densities.

At least for homogeneous freezing, the one-dimensional model predicts a wide range in ice number density between various regions of the cloud. In that case, the visible reflectance could still be determined by the zones of numerous, small ice crystals that scatter light more efficiently even though other properties, such as median ice number density, were determined mostly by sedimentation.

Finally, the results here contain both bad and good news for large-scale modeling of cirrus clouds. The bad news is that the requirement for extremely fine vertical resolution implies that even mesoscale models have far too coarse of a resolution to directly model cirrus clouds. The importance of sedimentation from rare temperature trajectories implies that parameterizations based on parcel models (e.g., Kärcher and Lohmann, 2003; Barahona and Nenes, 2009) probably miss essential physics.

The good news for large-scale modeling is that, in the onedimensional model, the ice number density below the cloud is much less sensitive to details of the microphysics than in a parcel model. There are new parameters required to describe sedimentation, such as the vertical extent of any supersaturated region below the cloud. But such parameters should be amenable to calculation by a three-dimensional model, although the required vertical resolution (perhaps tens of meters) is still more suitable for a local model than a global model.

Acknowledgements. This work was supported by NOAA base and climate funding.

Edited by: M. Krämer

\section{References}

Bacmeister, J. T., Eckermann, S. D., Tsias, A., Carslaw, K. S., and Peter, T.: Mesoscale temperature fluctuations induced by a spectrum of gravity waves: A comparison of parameterizations and their impact on stratospheric microphysics. J. Atmos. Sci., 56, 1913-1924, 1999.

Barahona, D. and Nenes, A.: Parameterizing the competition between homogeneous and heterogeneous freezing in ice cloud formation - polydisperse ice nuclei, Atmos. Chem. Phys., 9, 59335948, doi:10.5194/acp-9-5933-2009, 2009.

Barahona, D. and Nenes, A.: Dynamical states of low temperature cirrus, Atmos. Chem. Phys., 11, 3757-3771, doi:10.5194/acp11-3757-2011, 2011.

Cziczo, D. J., Froyd, K. D., Hoose, C., Jensen, E. J., Diao, M., Zondlo, M. A., Smith, J. B., Twohy, C. H., and Murphy, D. M.: Clarifying the dominant sources and mechanisms of cirrus cloud formation, Science, 340, 1320-1324, 2013.

DeMott, P. J., Rogers, D. C., and Kreidenweis, S. M.: The susceptibility of ice formation in upper tropospheric clouds to insoluble aerosol components, J. Geophys. Res., 102, 19575-19584, 1997.

Diao, M., Zondlo, M. A., Heymsfield, A. J., Beaton, S. P., and Rogers, D. C.: Evolution of ice crystal regions on the microscale based on in situ observations, Geophys. Res. Lett., 40, 34733478, 2013.

Froyd, K. D., Murphy, D. M., Lawson, P., Baumgardner, D., and Herman, R. L.: Aerosols that form subvisible cirrus at the tropical tropopause, Atmos. Chem. Phys., 10, 209-218, doi:10.5194/acp10-209-2010, 2010.

$\mathrm{Fu}$, Q. and Liou, K. N., Parameterization of the radiative properties of cirrus clouds, J. Atmos. Sci., 50, 2008-2025, 1993.

Fueglistaler, S., Luo, B. P., Voigt, C., Carslaw, K. S., and Peter, Th.: NAT-rock formation by mother clouds: a microphysical model study, Atmos. Chem. Phys., 2, 93-98, doi:10.5194/acp-293-2002, 2002.

Hoyle, C. R., Luo, B. P., and Peter, T.: The origin of high ice crystal number densities in cirrus clouds, J. Atmos. Sci., 62, 2568-2579, 2005.

Gensch, I. V., Bunz, H., Baumgardner, D. G., Christensen, L. E., Fahey, D. W., Herman, R. L., Popp, P. J., Smith, J. B., Troy, R. F., Webster, C. R., Weinstock, E. M., Wilson, J. C., Peter, T., and Krämer, M.: Supersaturations, microphysics, and nitric acid partitioning in a cold cirrus cloud observed during CR-AVE 2006: an observation-modeling intercomparison study, Environ. Res. Lett., 3, 1-9, 2008.

$\mathrm{Gu}$, Y. and Liou, K. N.: Interactions of radiation, microphysics, and turbulence in the evolution of cirrus clouds, J. Atmos. Sci., 57, 2463-2479, 2000.

Jensen, E. J. and Toon, O. B.: Ice nucleation in the upper troposphere: Sensitivity to aerosol number density, temperature, and cooling rate, Geophys. Res. Lett., 21, 2019-2022, 1994.

Jensen, E. J. and Toon, O. B.: The potential impact of soot particles from aircraft exhaust on cirrus clouds, Geophys. Res. Lett., 24, 249-252, 1997.

Jensen, E. J., Toon, O. B., Tabazadeh, A., Sachse, G. W., Anderson, B. E., Chan, K. R., Twohy, C. W., Gandrud, B., Aulenbach, S. M., Heymsfield, A. J., Hallett, J., and Gary, B.: Ice nucleation processes in upper tropospheric wave-clouds observed during SUCCESS, Geophys. Res. Lett., 25, 1363-1366, 1998. 
Jensen, E. J., Lawson, P., Baker, B., Pilson, B., Mo, Q., Heymsfield, A. J., Bansemer, A., Bui, T. P., McGill, M., Hlavka, D., Heymsfield, G., Platnick, S., Arnold, G. T., and Tanelli, S.: On the importance of small ice crystals in tropical anvil cirrus, Atmos. Chem. Phys., 9, 5519-5537, doi:10.5194/acp-9-5519-2009, 2009

Jensen, E. J., Pfister, L., Bui, T.-P., Lawson, P., and Baumgardner, D.: Ice nucleation and cloud microphysical properties in tropical tropopause layer cirrus, Atmos. Chem. Phys., 10, 1369-1384, doi:10.5194/acp-10-1369-2010, 2010.

Jensen, E. J., Pfister, L., and Bui T. P.: Physical processes controlling ice concentrations in cold cirrus near the tropical tropopause, J. Geophys. Res., 117, D11205, doi:10.1029/2011JD017319, 2012

Jensen, E. J., Lawson, R. P., Bergman, J. W., Pfister, L., Bui, T. P., and Schmitt C. G.: Physical processes controlling ice concentrations in synoptically forced, midlatitude cirrus, J. Geophys. Res., 118, 5348-5360, doi:10.1002/jgrd.50421, 2013 a.

Jensen, E. J., Diskin, G., Lawson, R. P., Lance, S., Bui, T. P., Hlavka D., McGill, M., Pfister, L., Toon, O. B., and Gao, R.: Ice nucleation and dehydration in the Tropical Tropopause Layer, P. Natl. Acad. Sci. USA, 110, 2041-2046, 2013b.

Kärcher, B.: Properties of subvisible cirrus clouds formed by homogeneous freezing, Atmos. Chem. Phys., 2, 161-170, doi:10.5194/acp-2-161-2002, 2002.

Kärcher, B. and Lohmann, U.: A parameterization of cirrus cloud formation: heterogeneous freezing, J. Geophys. Res., 108, 4402, doi:10.1029/2002JD003220, 2003.

Kärcher, B., Hendricks, J., and Lohmann, U.: Physically based parameterization of cirrus cloud formation for use in global atmospheric models, J. Geophys. Res., 111, D01205, doi:10.1029/2005JD006219, 2006.

Koop, T., Luo, B., Tsias, A., and Peter, T.: Water activity as the determinant for homogeneous ice nucleation in aqueous solutions, Nature, 406, 611-614, 2000.

Krämer, M., Schiller, C., Afchine, A., Bauer, R., Gensch, I., Mangold, A., Schlicht, S., Spelten, N., Sitnikov, N., Borrmann, S., de Reus, M., and Spichtinger, P.: Ice supersaturations and cirrus cloud crystal numbers, Atmos. Chem. Phys., 9, 3505-3522, doi:10.5194/acp-9-3505-2009, 2009.

Lin, R.-F., Starr, D. O., Reichardt, J., and DeMott, P. J.: Nucleation in synoptically forced cirrostratus, J. Geophys. Res., 110, D08208, doi:10.1029/2004JD005362, 2005.

Liou, K.-N.: Influence of cirrus clouds on weather and climate processes: A global perspective, Monthly Weather Rev., 114, 11671199, 1986.

Luo, B. P., Peter, Th., Wernli, H., Fueglistaler, S., Wirth, M., Kiemle, C., Flentje, H., Yushkov, V. A., Khattatov, V., Rudakov, V., Thomas, A., Borrmann, S., Toci, G., Mazzinghi, P., Beuermann, J., Schiller, C., Cairo, F., Di Don-Francesco, G., Adriani, A., Volk, C. M., Strom, J., Noone, K., Mitev, V., MacKenzie, R. A., Carslaw, K. S., Trautmann, T., Santacesaria, V., and Stefanutti, L.: Ultrathin Tropical Tropopause Clouds (UTTCs): II. Stabilization mechanisms, Atmos. Chem. Phys., 3, 1093-1100, doi:10.5194/acp-3-1093-2003, 2003.

Magee, N., Moyle, A. M., and Lamb, D.: Experimental determination of the deposition coefficient of small cirrus-like ice crystals near -50 C, Geophys. Res. Lett., 33, L17813, doi:10.1029/2006GL026665, 2006.
McFarquhar, G. M., Heymsfield, A. J., Spinhirne, J., and Hart, B.: Thin and subvisual tropopause tropical cirrus: Observations and radiative impacts, J. Atmos. Sci., 57, 1841-1853, 2000.

Murphy, D. M. and Gary, B. L.: Mesoscale temperature fluctuations and polar stratospheric clouds, J. Atmos. Sci., 52, 1753-1760, 1995.

Murphy, D. M.: Dehydration in cold clouds is enhanced by a transition from cubic to hexagonal ice, Geophys. Res. Lett., 30, 2230, doi:10.1029/2003GL018566, 2003.

Murray, B. J. and Bertram, A. K.: Formation and stability of cubic ice in water droplets, Phys. Chem. Chem. Phys., 8, 186-192, 2006.

Ren, C. and MacKenzie, A. R.: Cirrus parameterization and the role of ice nuclei, Q. J. Roy. Meteorol. Soc., 131, 1585-1605, 2005.

Sheridan, L., Harrington, J. Y., Lamb, D., and Sulia, K.: Influence of ice crystal aspect ratio on the evolution of ice size spectra during vapor depositional growth, J. Atmos. Sci., 66, 3732-3743, 2009.

Skrotzki, J., Connolly, P., Schnaiter, M., Saathoff, H., Möhler, O., Wagner, R., Niemand, M., Ebert, V., and Leisner, T.: The accommodation coefficient of water molecules on ice - cirrus cloud studies at the AIDA simulation chamber, Atmos. Chem. Phys., 13, 4451-4466, doi:10.5194/acp-13-4451-2013, 2013.

Sölch, I. and Kärcher, B.: A large-eddy model for cirrus clouds with explicit aerosol and ice microphysics and Lagrangian ice particle tracking, Q. J. Roy. Meteorol. Soc., 136, 2074-2093, 2010.

Spichtinger, P. and Gierens, K. M.: Modelling of cirrus clouds Part 1a: Model description and validation, Atmos. Chem. Phys., 9, 685-706, doi:10.5194/acp-9-685-2009, 2009a.

Spichtinger, P. and Gierens, K. M.: Modelling of cirrus clouds - Part 1b: Structuring cirrus clouds by dynamics, Atmos. Chem. Phys., 9, 707-719, doi:10.5194/acp-9-707-2009, 2009b.

Spichtinger, P. and Gierens, K. M.: Modelling of cirrus clouds - Part 2: Competition of different nucleation mechanisms, Atmos. Chem. Phys., 9, 2319-2334, doi:10.5194/acp-9-2319-2009, 2009c.

Spichtinger, P. and Cziczo, D. J.: Impact of heterogeneous ice nuclei on homogeneous freezing events in cirrus clouds. J. Geophys. Res., 115, D14208, doi:10.1029/2009JD012168, 2010.

Spichtinger, P. and Krämer, M.: Tropical tropopause ice clouds: a dynamic approach to the mystery of low crystal numbers, Atmos. Chem. Phys., 13, 9801-9818, doi:10.5194/acp-13-98012013, 2013.

Stackhouse, P. W. and Stephens, G. L.: A theoretical and observational study of the radiative properties of cirrus: Results from FIRE 1986, J. Atmos. Sci., 48, 2044-2059, 1991.

Ström, J., Seifert, M., Kärcher, B., Ovarlez, J., Minikin, A., Gayet, J.-F., Krejci, R., Petzold, A., Auriol, F., Haag, W., Busen, R., Schumann, U., and Hansson, H. C.: Cirrus cloud occurrence as function of ambient relative humidity: a comparison of observations obtained during the INCA experiment, Atmos. Chem. Phys., 3, 1807-1816, doi:10.5194/acp-3-1807-2003, 2003.

Vay, S. A., Anderson, B. E., Jensen, E. J., Sachse, G. W., Ovarlez, J., Gregory, G. L., Nolf, S. R., Podolske, J. R., Slate, T. A., and Sorens, C. E.: Tropospheric water vapor measurements over the North Atlantic during the Subsonic Assessment Ozone and Nitrogen Oxide Experiment (SONEX), J. Geophys. Res., 105, 3745-3755, 2000.

Wang, P.-H., McCormick, M. P., Poole, L. R., Chu, W. P., Yue, G. K., Kent, G. S., and Skeens, K. M.: Tropical high cloud charac- 
teristics derived from SAGE II extinction measurements, Atmos. Res., 34, 53-83, 1994.

Zhang, C. and Harrington, J. Y.: Including surface kinetic effects in simple models of ice vapor diffusion, J. Atmos. Sci., 71, 372390, 2014.
Zobrist, B., Weers, U., and Koop, T.: Ice nucleation in aqueous solutions of poly[ethylene glycol] with different molar mass, J. Chem. Phys., 118, 10254-10261, 2003. 